\title{
CONSTANTS OF RADIATION OF A UNIFORMLY HEATED INCLOSURE
}

\author{
By W. W. Coblentz
}

\section{THE COEFFICIENT OF TOTAL RADIATION}

In a previous paper ${ }^{1}$ was given a value of the coefficient, or so-called Stefan-Boltzmann constant, of total radiation of a uniformly heated inclosure, or so-called black body. This value $\left(\sigma=5.72 \times 10^{-12}\right.$ watt $\left.\mathrm{cm}^{-2} \mathrm{deg}^{-4}\right)$ was obtained by applying a correction, for reflection losses, to the data given in Table 6 of a previous publication. ${ }^{2}$ This correction for losses by reflection was taken to be I.2 per cent, irrespective of whether the surface of the receiver was covered with lampblack (soot) or electrolytically deposited platinum black. Subsequently, the data were recalculated (using the proper corrections for reflection of lampblack and of platinum black) and the results published elsewhere, ${ }^{3}$ the intention being to give the details more fully in this Bulletin. This is the object of the present paper, which gives further experimental data on atmospheric absorption, and also a discussion of other data, recently published.

.The data previously summarized ${ }^{4}$ are based upon about 600 independent measurements, made with Io receivers which, as already stated, were covered with either (I) a thin layer of lampblack or platinum black, smoked with soot, or (2) covered simply with an electrolytic deposit of platinum black.

The data obtained with receivers Nos. 8 and 9 are not included in the final value because, at the time the measurements were made, the apparatus was known to be defective, and hence the reliability of the results would be open to question.

To the data obtained with ro receivers, ${ }^{5}$ a correction of $\mathbf{I} .2$ per cent, for losses by reflection, were applied to measurements made with receivers covered with lampblack (soot), and a correction of $\mathrm{I} .7$ per cent to measurements made with receivers covered with platinum black. The reflection from a receiver covered with

${ }^{1}$ Bulletin, Bureau of Standards, 12, p. 553; 1916.

${ }^{2}$ Coblentz and Emerson, Bulletin, Bureau of Standards, 12, p. 549; 1916.

3 Proc. Nat. Acad. Sci., 3, p. 504; 1917.

Bulletin, Bureau of Standards, 12, p. 549; 1916 (Table 6).

5 Erroneously stated to be nine receivers in Proc. Nat. Acad. Sci., 3, p. 504; 1917. 
platinum black, then smoked, is $\mathbf{I . 2}$ per cent. These corrections were determined by direct measurements upon some of the receivers, and by comparison of the surfaces of the other receivers with samples of lampblack whose reflection losses had been determined in a previous investigation. ${ }^{6}$

As mentioned in the first description of the apparatus used in making these measurements, ${ }^{7}$ the edges of the slits over the sides of the receiver were beveled, and painted with lampblack on the beveled surface. This should absorb the radiations reflected in that direction from the receiver. Nevertheless, at this writing, it is an open question whether the loss by reflection is as large as it would be if no beveled edges were present. This might cause a slight over correction (say o.I per cent) of the data as now published, but it would be no greater than the variations in the reflectivity of the various surfaces from the mean value herein adopted.

The original data (from Table 6 , loc. cit.), corrected for reflection as just described, are assembled in Table $\mathrm{I}$. It does not include a set of measurements made on an unblackened porcelain radiator, (Series CXLVIII to CLI). However, applying a correction (amounting to I per cent) for lack of blackness, ${ }^{8}$ the observations are close to those obtained on a blackened radiator.

The value of the coefficient of total radiation, after applying the corrections just mentioned is

$$
\sigma=(5.722 \pm 0.012) \times \mathrm{IO}^{-12} \text { watt } \mathrm{cm}^{-2} \mathrm{deg}^{-4} .
$$

No correction was made for atmospheric absorption, in view of the fact that the measurements had been made in the winter when the humidity was low. Furthermore, by means of phosphorous pentoxide, the water vapor had been removed from the apparatus, which was of quite air-tight construction.

Subsequent to this investigation, further consideration was given to the question of absorption by dry air. ${ }^{9}$ The correction for absorption by dry air was determined by observing the transmission through a brass tube $6 \mathrm{~cm}$ in diameter and $5 \mathrm{I} \mathrm{cm}$ long, the ends of which were covered with windows of clear rock salt. This tube was evacuated with an oil pump and then filled with air which had been passed through phosphorous pentoxide. It therefore contained only carbon dioxide, which may cause a small amount of absorption.

6 Bulletin, Bureau of Standards, 9, p. 283; rgra.

${ }^{7}$ Bulletin, Bureau of Standards, 12, p. 507 (Fig. 2); 1916.

${ }^{8}$ Bulletin, Bureau of Standards, 12, p. 57 1; 1916.

9 Loc. cit. See note 3 . 
TABLE 1.-Summary of the Dimensions of the Receivers and of the Slits, the Kind of Absorbing Surfaces, and the Results Obtained with Each Receiver

[Receivers 1, 3, and 5 are of manganin or "therlo"; the others are of platinum]

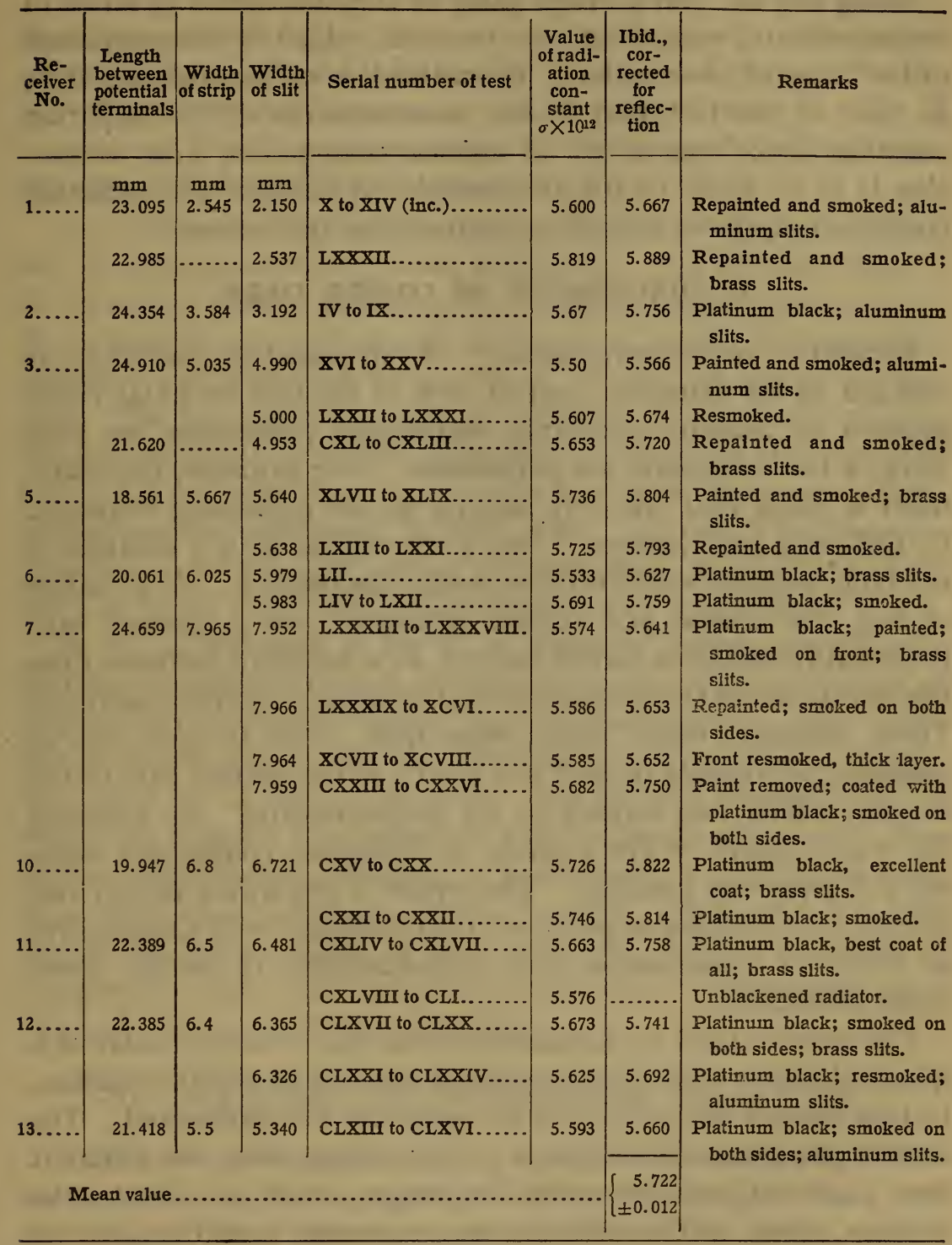

The transmission was determined by noting a series of galvanometer deflections caused by black-body radiation $\left(800^{\circ} \mathrm{C}\right)$ which was passed through the evacuated tube and focused upon a linear thermopile of bismuth-silver. Immediately thereafter a stopcock was opened and either dried or undried air was permitted to enter, under atmospheric pressure. 
Using air containing $9.95 \mathrm{~g}$ of water per cubic meter, the absorption amounted to about 0.9 per cent.

Using dry air, the average value of the absorption ( 3 series of measurements) was about 0.09 per cent, which is the magnitude of the errors of observation. From this it is to be concluded that, in view of the fact that in the measurements of the radiation constant the column of dry air was less than $50 \mathrm{~cm}$, if any correction is to be made to the aforementioned value of the radiation coefficient, $\sigma$, it can hardly be greater than o.I per cent.

\section{DISCUSSION OF OTHER DATA}

Recently a new determination ${ }^{10}$ of this radiation constant was brought to my attention, and in view of the fact that this paper appears to contain inaccurate statements concerning my own work, a few comments are permissible. For example, the statement is made that the only novelty in the apparatus employed by Coblentz and Emerson ${ }^{11}$ was a thermopile with a continuous receiving surface; which is of secondary importance. As a matter of fact, the crucial part of the apparatus was a receiver with potential terminals attached thereto, at a sufficient distance from the ends to avoid the question of heat conduction to the electrodes. These potential wires, which were from 0.003 to $0.02 \mathrm{~mm}$ in diameter, accurately defined the length of the central part of the receiver which was utilized in the measurements. By exposing the whole length of the receiver to radiation, conduction losses did not enter the problem. The writer is not aware of any one having used a similar apparatus which compares with this receiver in nicety of construction, and reproducibility of results under given conditions.

The receiver used by Kahanowicz was placed at the center of a spherical mirror ${ }^{12}$ with an opening in one side to admit radiation. In this manner the correction for reflection was eliminated. The shutter was close to the receiver. If its temperature was different from that of the water-cooled diaphragm, which was before the radiator, errors in the radiation measurements would occur. As mentioned in previous papers, ${ }^{13}$ the shutter should be placed between the water-cooled diaphragm and the radiator, to avoid

\footnotetext{
${ }^{10}$ Kahanowicz, Nuovo Cimento (6), 13, p. 142, 1917; Naples.

11 Bulletin, Bureau of Standards, 12, p. 506; 1916.

12 Bulletin, Bureau of Standards, 12, p. 509; 1916. Use of hemispherical mirrors is discussed.

13 Bulletin. Bureau of Standards, 12, p. 514; 1916.
} 
a change in surroundings facing the receiver when the shutter is raised for making the radiation measurements.

The temperature range was from 260 to $530^{\circ} \mathrm{C}$. The distance from the radiator to the receiver was 35 to $55 \mathrm{~cm}$. A series of 28 measurements gave an average value of $\sigma=5.6 \mathrm{I} \times \mathrm{IO}^{-12}$ watt $\mathrm{cm}^{-2} \mathrm{deg}^{-4}$. Of this number I I gave a value of $\sigma=5.7$. Out of a series of 4 measurements made in December, 1916, with the distance $d=56 \mathrm{~cm}, 3$ gave a value of $\sigma=5.7$.

No corrections were made for atmospheric absorption, which for the temperatures used is not negligible. In a previous paper ${ }^{14}$ it was shown that on removing the moisture (vapor pressure of ro to $12 \mathrm{~mm}$ ) from a column of air $52 \mathrm{~cm}$ in length, the radiation constant was increased from $\sigma=5.4$ I to 5.55 , or about 2.6 per cent. For the spectral region transmitted by rock salt, to $5^{\mu}$, the experimental data, just described, indicate an absorption of about 0.9 per cent, depending upon the vapor pressure. Other measurements mentioned in the paper just cited indicate an absorption of 2 to 3 per cent of the radiations emitted by a black body at $1000^{\circ} \mathrm{C}$ for the average humidity of Washington.

Dr. H. H. Kimball, of the U. S. Weather Bureau, very kindly sent me comparative data showing that the vapor pressures at Naples are considerably higher than at Washington. From these data it would appear that the corrections for atmospheric absorption must be at least I per cent. For the low temperatures at which the radiator was operated, a fair estimate of the correction to the radiation data obtained by Kahanowicz is $\mathrm{r} .5$ to 2 per cent, or a value of $\sigma=5.69$ to $5.72 \times \mathrm{IO}^{-12}$ watt $\mathrm{cm}^{-2} \mathrm{deg}^{-4}$. In other words the Naples value of the coefficient of total radiation is comparable with other recent determinations ${ }^{15}$ which indicate a value of $\sigma=5.7 \times \mathrm{IO}^{-12}$ watt $\mathrm{cm}^{-2} \mathrm{deg}^{-4}$.

\section{THE CONSTANT OF SPECTRAL RADIATION}

During the past year a further examination was made of the accuracy of the factors used in converting the previously observed ${ }^{16}$ prismatic spectral-energy data into the normal energy distribution. The graphical methods previously employed were checked, and similar factors were obtained by computation, using the first differential of the dispersion formula, which best repre-

14 Bulletin, Bureau of Standards, 12, p. 576; 19r6. See Table 3, Series CLXXX to CLXXXII.

${ }^{15}$ Millikan, Phys. Rev., 7, p. 379, I916, quotes a value of $\sigma=5.67$, by Westphal.

${ }^{10}$ Bulletin, Bureau of Standards, 10, p. 2: 1913. 
sents the observed refractive indices of fluorite. ${ }^{17}$ These refractive indices were obtained from consideration of all the available data, which in the region of $\mathrm{I}$ to $2 \mu$ are represented by the curve published by Langley and Abbot. ${ }^{18}$ The best dispersion formula is that of Paschen. ${ }^{19}$ However, owing to incompleteness of the formula, the graphical method is just as accurate as is the method of computation.

The conclusion arrived at is that the spectral radiation constant, $C_{2}=14353$ micron degrees, determined some years ago, ${ }^{20}$ remains unchanged. However, at this writing there is some doubt as to whether some of the corrections then applied should have been made, giving a value of $C_{2}=14369$. In view of the uncertainty of the temperature scale, and of the different experimental methods employed, the mean of the values of this constant, which have been used by Reichsanstalt and by this Bureau, viz, $C_{2}=14325$, is probably close to the true value. For example, from a consideration of related experimental data, as will be shown in a forthcoming paper, ${ }^{21}$ the above determined value of $\sigma=5.72$ indicates a value of $C_{2}=\mathrm{I} 432 \mathrm{O}$. The observations on the coefficient of total radiation were made at less than $1000^{\circ} \mathrm{C}$, and hence do not require a correction to the temperature scale. Moreover, because of the difficulty in eliminating reradiation, the observed values of diffuse reflection, of long wave-length radiation, are higher than the true value.

\section{SUMMARY}

The object of this paper is to give experimental data on atmospheric absorption as it affects the measurements of the radiation constants.

The paper gives also a recalculation of the coefficient of total radiation of a uniformly heated inclosure, taking into consideration all losses by reflection from the receivers, as well as losses by atmospheric absorption. The value of the coefficient of total radiation on recalculation is

$$
\sigma=(5.722 \pm 0.012) \times \mathrm{IO}^{-12} \text { watt } \mathrm{cm}^{-2} \mathrm{deg}^{-4},
$$

which is the same as previously published.

\footnotetext{
17 Bulletin, Bureau of Standards, 10, p. 39. In table 5 , the value of the refractive indices at $\lambda=4.4 \mu$, $4.6 \mu$, and $5.0 \mu$ should be, respectively, 8,7 , and 8 , instead of 3,5 , and 0 , in the last decimal place, as previously published.

${ }^{18}$ Annals, Astrophys. Obs., 1, p. 222, P1. XXVIB.

19 Paschen, Ann. der Phys., 4, p. 299, rgor: Fl. II.

20 Bulletin, Bureau of Standards, 13, p. 466: 1916.

21 Bureau of Standards Scientific Paper, Methods of Computing and Intercomparing Radiation Data.
} 
The effect of atmospheric absorption upon data obtained at Naples is discussed, and it is concluded that, if a correction is made for absorption by water vapor, the value of $\sigma$, obtained at that station, is of the order of $\sigma=5.7$. This is about the average value of all observers when corrections are made for atmospheric absorption.

The present status of the constant of spectral radiation is discussed, and the conclusion arrived at is, that, in view of the uncertainty of the temperature scale, and of the different experimental methods used, the mean of the values of this constant, which have been used by Reichsanstalt and by this Bureau, viz, $C_{2}=\mathrm{r} 4325$, is probably close to the true value.

WaSHINGTON, August i i, I9I9. 